\title{
Denegación de la guarda y custodia compartida de un perro por Sentencia del Juzgado de Primera Instancia no 40 de Madrid.
}

\author{
Ana Sanz Rojas ${ }^{1}$. \\ Letrada de la parte demandada y socia del despacho ABA Abogadas, especialista en Derecho \\ de familia, laboral y civil.
}

Con fecha 5 de septiembre de 2012, el demandante interpone demanda ante el Juzgado de Primera Instancia de Madrid, solicitando que se le declare como único propietario del perro que convivía con él y con mi representado, proponiendo abonar a mi mandante la cantidad de 250.-euros.

Subsidiariamente, se solicitaba la declaración de la tenencia compartida del animal copropiedad de ambos litigantes, estableciendo iguales periodos de tiempo para que permanezca el perro en compañía de uno y otro, con la obligación de hacerse cargo personalmente del animal y convivir con él sin delegar el cuidado a terceras personas. Es decir, se estaba solicitando la guarda y custodia compartida del animal.

Para determinar la posibilidad de una tenencia compartida del animal, resultaba imprescindible acreditar con carácter previo la copropiedad del animal. La demanda rectora del procedimiento daba por hecho esta copropiedad, siendo precisamente el objeto de discusión por parte de mi representado, al ser el único propietario del animal.

Se citó a las partes a comparecencia de juicio verbal, donde esta letrada se opuso a la demanda presentada de contrario, solicitando que se declarase la titularidad exclusiva de mi mandante sobre el perro, y se desestimara íntegramente la demanda interpuesta de contrario.

En efecto, el demandante y mi representado tuvieron una relación de pareja, y durante la misma un familiar de mi mandante le regaló el perro.

\footnotetext{
${ }^{1}$ Ana Sanz es Licenciada en Derecho en el año 2002 por la Universidad de Alcalá de Henares de Madrid. Tras un año de ejercicio en otro despacho profesional, se incorpora a ABA Abogadas (http://abaabogadas.com/) en febrero de 2004. Desde esta fecha, además de otros asuntos civiles y derecho laboral, ha ido especializándose en derecho de familia y liquidación de gananciales. Ha ido ocupando puestos de creciente responsabilidad en ABA Abogadas y en 2010 fue nombrada asociada por ABA Abogada y Asociadas. En junio de 2012 fue distinguida como Socia de ABA. Está colegiada en el Ilustre Colegio de Abogados de Madrid.
} 
De conformidad con lo establecido en los artículos 618 , siguientes y concordantes del Código Civil $^{2}$, la donación es un acto de liberalidad por el cual una persona dispone gratuitamente de una cosa a favor de otra que la acepta.

La donación se perfecciona desde que el donante conoce la aceptación del donatario, pudiendo ser verbal cuando se trate de cosa mueble. Siendo, en cualquier caso, un modo válido de adquirir la propiedad de conformidad con lo dispuesto en el Código civil.

Así, sin perjuicio de que ambas partes mantuvieran una relación de pareja, los bienes adquiridos por una parte son privativos en cualquier caso, toda vez que al no mediar matrimonio ni unión de hecho no podemos entender que exista una sociedad de gananciales o situación análoga.

Pero, a mayor abundamiento, de conformidad con lo establecido en el artículo 1.346 del Código civil, cualquier bien adquirido por título de donación es privativo.

\section{1.- Prueba practicada en el procedimiento.}

La prueba practicada en el procedimiento acreditó que mi mandante era la única propietaria del animal.

La identificación del perro constaba a nombre exclusivo de mi representado, como constaba en el microchip con número de identificación ${ }^{3}$. Y así fue certificado a instancias del demandante por la clínica veterinaria que lo implantó, constando expresamente la titularidad exclusiva de mi representado en el oficio que la clínica remitió al Juzgado.

Del mismo modo, y según oficio remitido igualmente al Juzgado en el presente procedimiento se hace constar que, aunque en el registro de animales de compañía emitido por el colegio de veterinarios de Madrid, aparece el teléfono del demandante como segundo teléfono, es el de mi representado el que aparece en primer término, constando como único propietario del animal, mi representado.

Prueba asimismo de la titularidad exclusiva de mi mandante, lo constituye el hecho de que en la cartilla sanitaria y de identificación oficial de animales aparezca como única propietaria del perro, y que el mismo estuviera domiciliado en su domicilio, constando el domicilio de la familia de mi representado como domicilio del perro en la tarjeta expedida por el registro de animales de compañía del Ayuntamiento.

Además, el perro cuenta con un seguro de responsabilidad incluido en la póliza del seguro de hogar de la familia de mi representado, constando nuevamente como única propietaria la demandada.

\footnotetext{
${ }^{2}$ Código Civil: http://www.derechoanimal.info/bbdd/Documentos/605.doc

${ }^{3}$ Puede consultarse la legislación autonómica aplicable a esta materia, bajo la voz "Identificación", en: http://www.derechoanimal.info/esp/basededatos/index
} 
También se practicó en el acto de la vista la testifical de la persona que había donado al perro, quien manifestó que el "regalo" se había realizado exclusivamente a mi representado, significando además que desconocía que el demandante fuera su pareja. Es más, la propia demandante reconoció que el perro había sido un regalo de este familiar.

El resto de prueba practicada en el procedimiento (documental y oficios solicitados por el demandante), únicamente acreditan que el demandante en algunas ocasiones sufrago gastos del perro, pero no olvidemos que durante ese periodo existía una convivencia de pareja en la que se compartían no sólo los gastos del animal, sino también el resto de gastos de dicha convivencia, sin que la asunción de dichos gastos pueda determinar la copropiedad del perro.

\section{2.- Fundamentación jurídica de la sentencia}

De acuerdo con la doctrina jurisprudencial en cuanto a los criterios a seguir en la liquidación de las uniones de hecho, que declara que debe estarse a los pactos que hayan existido entre las partes relativos a la organización económica de cara a una posterior liquidación de dichas relaciones, no siendo en modo alguno aplicable el régimen de sociedad de gananciales (aunque incluso aplicándolo el bien donado sería igualmente privativo).

Igualmente, señala dicha jurisprudencia que cabe entender comunes todos o algunos de los bienes adquiridos durante la convivencia siempre que pueda deducirse una voluntad inequívoca en este sentido. Voluntad que no existe en el presente supuesto, cuando en todos y cada uno de los documentos del animal consta como única titular del mismo mi representado.

\section{Como regla general, los bienes adquiridos durante la convivencia no se convierten en comunes, perteneciendo a quien los ha adquirido.}

En consecuencia, constando acreditada la propiedad del perro por parte de mi representado, en base a la donación efectuada, no puede prosperar la demanda interpuesta, ya que el artículo 394 del Código civil establece el derecho de uso de los condueños, siendo por tanto necesario acreditar la copropiedad del animal. 